LIBRES: Library and Information Science Research

Electronic Journal ISSN 1058-6768

1999 Volume 9 Issue 2; September 30.

Bi-annual LIBRE9N2

\title{
Further investigations into the first-citation process: the case of population genetics
}

\author{
Bry Mohan Gupta \\ National Institute of Science, Technology and Development Studies \\ Dr. K.S. Krishnan Marg, New Delhi 110012, India \\ E-mail: bmg@csnistad.ren.nic.in \\ and \\ Ronald Rousseau \\ KHBO, Zeedijk 101, 8400 Oostende, Belgium, and \\ UIA, IBW, Universiteitsplein 1, 2610 Wilrijk, Belgium \\ E-mail: ronald.rousseau@kh.khbo.be
}

\begin{abstract}
In this article the first-citation process is investigated. Former studies led to two double exponential models for this process. The first model resulted in a concave function, the other one in a function with an inflection point (an S-shaped function). Real data using a year as time unit could best be described by the first model, data using two weeks as a unit could best be described by the second one. In this note we show that for a group of nine related data sets in the field of population genetics, using one year as a unit, the first observation is confirmed: the concave model can adequately describe such data.
\end{abstract}




\section{Introduction}

Science is cumulative in nature: each new research article is built on the foundation of previous articles (and/or books). An author acknowledges this by referring to these articles and books in a reference list. The study of this 'scholarly bricklaying', as Price (1963) calls it, is known as citation analysis. Citation analysis studies different aspects of the 'Citation Culture' (Wouters, 1999): motivations for citing, the citation network as a mathematical graph, statistical aspects of citations and references, mappings of the citation network, etc... For reviews on citation analysis and a theory of citation we refer the reader to (Egghe and Rousseau, 1990; Liu, 1993; Leydesdorff, 1998; Wouters, 1999).

In previous studies (Rousseau 1993,1994) we investigated the first-citation process. Under the term 'first-citation process' we mean the abstract process that shifts a published article from the 'uncited' to the 'cited' group. As described in (Rousseau, 1994), the publication of an article (or group) of articles can be considered as the introduction of a stimulus in an abstract 'information space' (perhaps Popper's World III). Then citations, as symbols for 'use' can be interpreted as responses to this stimulus. In particular, the first citation is the first sign of response. It is a token that the article is not left unnoticed. One can also say that articles that have been cited (at least once) have past an initial filter. Perhaps this filter separates the totally unused (unnoticed?) articles from the other ones, having presumably more (scientific) potential.

A statistical study of the cumulative first-citation distribution of a group of articles led to two double exponential models: one resulting in a concave function, the other one resulting in a function with an inflection point (an S-shaped function). Real data using a year as time unit could best be described by the first model, data using two weeks as a unit could best be described by the second one. These observations, though, were only based on two data sets. In this note we will show that for a group of nine related data sets, using one year as a unit, the first observation is confirmed. The first model can adequately describe such data. This model implies that the rate of conversion from the set of articles that have been cited to those that have not, is a decreasing function of time.

The first-citation process as described here has not received much attention in the scientific literature. Yet, Moed and Van Raan (1986) and Schubert and Glänzel (1986) did consider the time between publication and first citation as a journal indicator of immediacy. Moreover, Glänzel (1992) found that the mean of the first response determined to a large extent the complete citation distribution. In his study Glänzel used stopping times (a special kind of random variables (Egghe, 1984)), which lead to a considerably more sophisticated approach than the simple statistical procedure used here and in our earlier study (Rousseau, 1994).

\section{Data}


Source articles were taken from the "Bibliography of Theoretical Population Genetics" (Felsenstein, 1981.) This bibliography was selected as the source of our investigation because it comprehensively covers the publications in the field of theoretical population genetics from 1870 to 1980 . However, the only source for collecting citation data is ISI's Science Citation Index, which is only available from 1955 (leaving the retrospective SCI covering 1945-1954 aside.) As a result the period of study is restricted to 1955-1980. Moreover, as citation data were collected manually only a selected set of data was studied. Concretely: we only investigated the articles (from the bibliography) published in 1955, 1958, 1961, ...1979, with a three-year interval. The resulting nine related databases suffice largely for the purpose of this study. We refer the reader to e.g. (Gupta, 1997; Gupta et al., 1998; Kretschmer \& Gupta, 1998), where this bibliography has been studied from other points of view. Complete citation data on which our investigation is based are presented in the appendix.

\section{Preliminary remarks on the percentage of uncited articles}

Before explaining the model we would like to point out another aspect of the data. A certain percentage of articles will always remain uncited. Yet, it seems that for earlier articles a smaller percentage remains uncited. This is clearly shown in Table 1. In the years 1955,1958 and 196115 to $23 \%$ of the articles remains uncited over a period of approximately 18 years, while for later years this percentage is considerably higher. We are unable to suggest an explanation for this. Note also that the term 'uncited' really means 'uncited by journals covered by the ISI database'.

Table 1 Percentages of uncited articles (each considered over a period of approximately 18 years)

\begin{tabular}{|c|c|c|c|c|}
\hline year & $\begin{array}{c}\text { number of } \\
\text { articles }\end{array}$ & $\begin{array}{c}\text { number of } \\
\text { cited articles }\end{array}$ & $\begin{array}{c}\text { number of } \\
\text { uncited articles }\end{array}$ & $\begin{array}{c}\text { percentage of } \\
\text { uncited articles }\end{array}$ \\
\hline 1955 & 75 & 64 & 11 & 14.7 \\
\hline 1958 & 77 & 64 & 13 & 16.9 \\
\hline 1961 & 122 & 94 & 28 & 23.0 \\
\hline 1964 & 167 & 115 & 52 & 31.1 \\
\hline 1967 & 301 & 202 & 99 & 32.9 \\
\hline 1970 & 324 & 203 & 121 & 37.3 \\
\hline 1973 & 418 & 282 & 136 & 32.5 \\
\hline 1976 & 465 & 307 & 158 & 34.0 \\
\hline 1979 & 483 & 338 & 145 & 30.0 \\
\hline
\end{tabular}

The model (Rousseau, 1994)

Consider a fixed group of $\mathrm{N}$ articles. Let $\mathrm{C}(\mathrm{t})$ be the cumulative number of articles cited at least once (in journals covered by ISI) over a period of length $t$ years. We 
assume that the change in $\mathrm{C}(\mathrm{t})$ is proportional to the number of uncited articles, with a time-dependent proportionality factor $q(t)=A e^{-a t}, a^{3} 0, A>0$. This factor can be interpreted as a conversion factor. This conversion factor is assumed to be exponentially decreasing. It describes the rate at which articles shift from the uncited group to the cited one. Putting $R(t)=C(t) / N$ leads to the following differential equation:

$$
\frac{d R(t)}{d t}=A e^{-a t}(1-R(t))
$$

The solution of this differential equation is the function:

$$
R(t)=1-k b^{\left(1-e^{-a r}\right)}
$$

where $k=1-R(0)$, and $b=e^{-A / a}$. For the proof we refer to (Rousseau, 1993,1994). Note further that

$$
\lim _{t \rightarrow \infty} R(t)=1-k b \leq 1
$$

This means that in this model not all articles need ever be cited, which is a realistic assumption. Indeed, the model predicts that $100 \mathrm{~kb} \%$ of all published articles will remain uncited. In (Rousseau, 1993,1994) we have shown that citations to Russian language library science periodicals, as published by Motylev (1981), fitted this equation quite well.

\section{The conversion factor}

Before we turn to the results of the fitting exercise we would like to have another look at the data to see if they indeed suggest an exponentially decreasing conversion factor from the group of cited articles to the group of uncited ones. Table 2 gives the cumulative percentages of cited articles in the first five years after publication. It is clear that this percentage increases more and more slowly. After 5 years more than $80 \%$ of all citations have occurred. Because of this characteristic of the data we were able to fit the double exponential model.

Table 2. Cumulative percentages of cited articles (CPCA) in the first five years after publication

\begin{tabular}{|c|c|c|c|c|c|c|c|c|c|}
\hline $\begin{array}{c}\text { CPCA } \\
\text { in }\end{array}$ & 1955 & 1958 & 1961 & 1964 & 1967 & 1970 & 1973 & 1976 & 1979 \\
\hline $\begin{array}{c}\text { first } \\
\text { year }\end{array}$ & 16.0 & 9.1 & 6.6 & 3.0 & 12.0 & 5.6 & 9.1 & 13.1 & 6.0 \\
\hline
\end{tabular}




\begin{tabular}{|c|c|c|c|c|c|c|c|c|c|}
$\begin{array}{c}\text { first 2 } \\
\text { years }\end{array}$ & 38.7 & 28.6 & 32.8 & 24.0 & 33.6 & 22.5 & 26.3 & 35.9 & 45.8 \\
\hline $\begin{array}{l}\text { first 3 } \\
\text { years }\end{array}$ & 54.7 & 41.6 & 47.5 & 40.1 & 44.9 & 35.5 & 42.8 & 49.2 & 56.9 \\
\hline $\begin{array}{l}\text { first 4 } \\
\text { years }\end{array}$ & 60.0 & 50.6 & 58.2 & 50.3 & 50.5 & 41.4 & 48.8 & 55.1 & 60.9 \\
\hline $\begin{array}{c}\text { first 5 } \\
\text { years }\end{array}$ & 65.3 & 59.7 & 61.5 & 55.1 & 53.8 & 45.1 & 53.8 & 60.0 & 64.0 \\
\hline
\end{tabular}

\section{Results}

In order to fit our double exponential model we have to find values for the parameters $k, b$ and $a$. Moreover $A=-a \ln (b)$. Table 3 presents the results of $a$ non-linear least squares fit based on Marquardt's algorithm (Marquardt, 1963). Fig. 1 illustrates the case of the 1973 data.

Table 3. Parameter values of best fitting curves

\begin{tabular}{|c|c|c|c|c|c|c|}
\hline data set & $\mathrm{k}$ & $\mathrm{b}$ & $\mathrm{a}$ & $\mathrm{A}$ & $\mathrm{R}^{2}$ & $1-\mathrm{kb}$ \\
\hline 1955 & 0.828 & 0.200 & 0.200 & 0.32 & 0.992 & 0.83 \\
\hline 1958 & 0.917 & 0.147 & 0.141 & 0.27 & 0.998 & 0.87 \\
\hline 1961 & 0.930 & 0.241 & 0.253 & 0.36 & 0.998 & 0.78 \\
\hline 1964 & 0.981 & 0.321 & 0.290 & 0.33 & 0.998 & 0.69 \\
\hline 1967 & 0.872 & 0.389 & 0.310 & 0.29 & 0.997 & 0.66 \\
\hline 1970 & 0.930 & 0.401 & 0.216 & 0.20 & 0.991 & 0.63 \\
\hline 1973 & 0.913 & 0.352 & 0.265 & 0.28 & 0.997 & 0.68 \\
\hline 1976 & 0.869 & 0.393 & 0.408 & 0.38 & 0.999 & 0.66 \\
\hline 1979 & 0.934 & 0.332 & 0.600 & 0.66 & 0.994 & 0.69 \\
\hline
\end{tabular}

Judging by the high $R^{2}$-values we may assume that equation (2) yields an adequate representation of the first-citation process. This at least if data are collected on a yearly basis. This assumption is confirmed by a graphical analysis of the best fitting curves to the data (cf. Fig.1).

These results predict that from 1964 on, about $30 \%$ of all articles presented in Felsenstein's bibliography will never be cited in journals covered by ISI. Before that time this percentage is lower (between 10 and 20\%). This is in accordance with the data (as described in a previous section). 


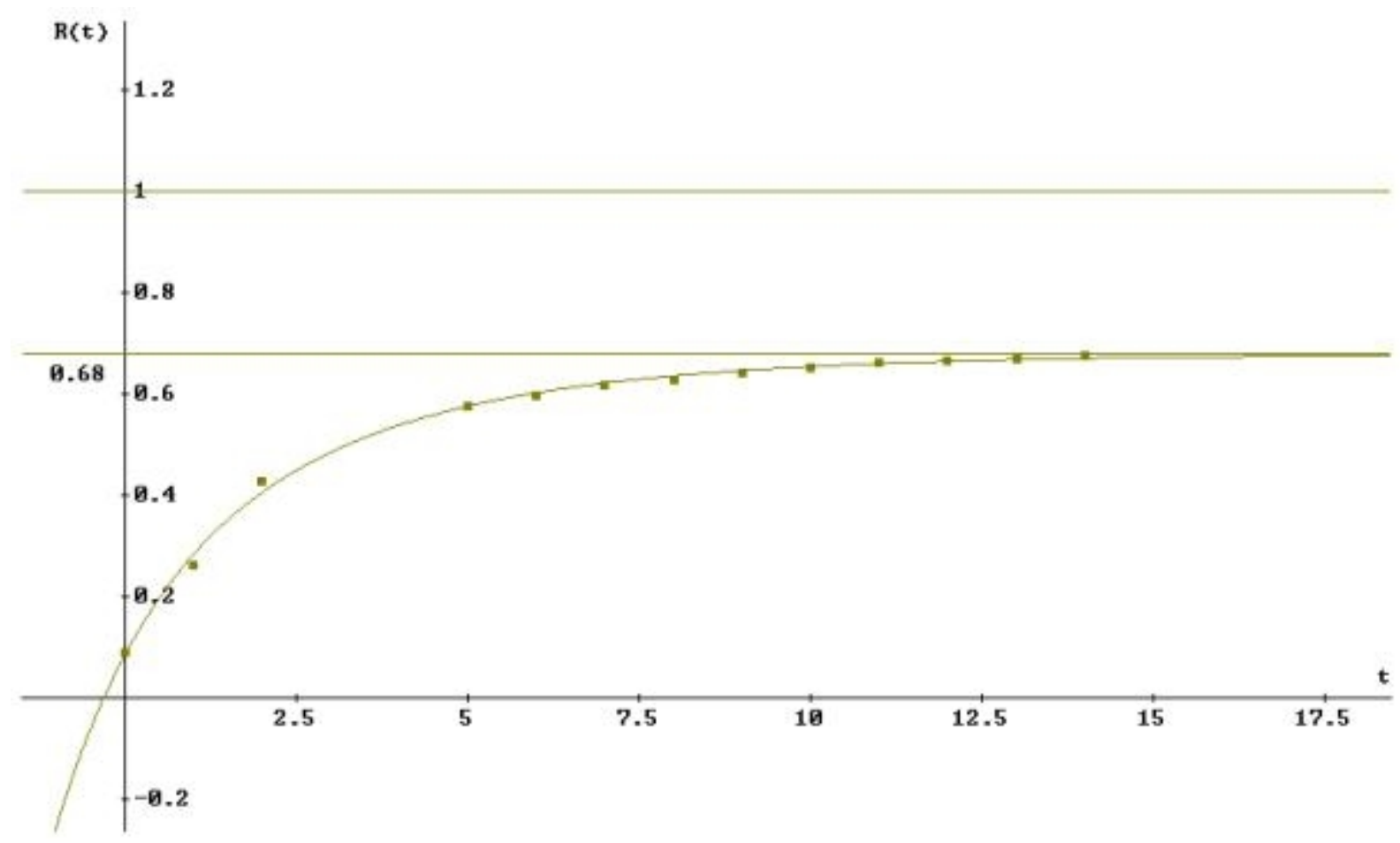

Fig.1 Best fitting curve and asymptote indicating limiting value (0.68) for 1973 first-citation data

\section{Conclusions and suggestions for further research}

We have shown that, for data in the field of population genetics, the first double exponential model as studied in (Rousseau 1993,1994) adequately describes firstcitation data, collected on a yearly basis.

Most articles, except some publications in e-journals, suffer from a publication delay between the acceptance (after peer review) of the manuscript and its actual publication. This, clearly, has an influence on the time between publication and first citation (it is the publication delay of the citing article that is important here). Hence, it would be interesting to study this influence, e.g. by comparing first-citations for articles in e-journals and for other articles. Note that the mechanism that is at work here (considered from a model-theoretic point of view) is the convolution of two distributions. This mechanism has been explained in (Rousseau, 1998) and studied in a citation context in (Egghe and Rousseau, 2000).

\section{Acknowledgement}

The authors thank an anonymous referee for a number of pertinent observations leading to a more readable article. 


\section{References}

Egghe, L. (1984). Stopping time techniques for analysts and probabilists. Cambridge (UK): Cambridge University Press.

Egghe,L. and Rousseau, R. (1990). Introduction to Informetrics. Quantitative methods in library, documentation and information science. Amsterdam: Elsevier.

Egghe,L. and Rousseau,R. (2000). The influence of publication delays on the observed ageing distribution of scientific literature. Journal of the American Society of Information Science (to appear).

Felsenstein, J. (1981). Bibliography of Theoretical Population Genetics. Stroudsburg (PA): Dowden, Hutchinson \& Ross.

Glänzel, W. (1992). On some stopping times of citation processes. From theory to indicators. Information Processing \& Management, 28, 53-60.

Gupta, B.M. (1997). Analysis of distribution of the age of citations in theoretical population genetics. Scientometrics, 40(1), 139-162.

Gupta, B.M., Kumar, S. \& Rousseau, R. (1998). Applicability of selected probability distributions to the number of authors per article in theoretical population genetics. Scientometrics, 42(3), 325-334.

Kretschmer, H. and Gupta, B.M. (1998). Collaboration patterns in theoretical population genetics. Scientometrics, 43(3), 455-462.

Leydesdorff, L. (1998) Theories of citation? Scientometrics, 43, 5-25.

Liu, M. (1993). The complexities of citation practice: a review of citation studies. Journal of Documentation, 49, 370-408.

Marquardt, D.W. (1963). An algorithm for least squares estimation of nonlinear parameters. Journal of the Society of Industrial and Applied Mathematics, 2, 431-441.

Moed, H. and Van Raan, A. (1986). Cross-field impact and impact delay of physics departments. Czechoslovak Journal of Physics B, 36, 97-400.

Motylev, V.M. (1981). Study into the stochastic process of change in the literature citation pattern and possible approaches to literature obsolescence estimation. International Forum on Information and Documentation, 6, 3-12.

Price, D. J. de Solla (1963). Little Science, Big Science. New York: Columbia University Press. 
Rousseau, R. (1993). Double exponential models for first-citation processes. Report University of Antwerp (UIA). \{ copies available from the author $\}$

Rousseau, R. (1994). Double exponential models for first-citation processes. Scientometrics, 30(1), 213-227.

Rousseau, R. (1998). Convolutions and their applications in information science. The Canadian Journal of Information and Library Science/Revue canadienne des sciences de l'information et de bibliothéconomie, 23(3), 29-47.

Schubert, A. and Glänzel, W. (1986). Mean response time - a new indicator of journal citation speed with application to physics journals. Czechoslovak Journal of Physics B, 36, 121-125.

Wouters, P. (1999). The Citation Culture. Ph. D. Thesis. Universiteit van Amsterdam. 


\section{Appendix}

Each table presents, for a different publication year, the total number of source journals, and, for all years, starting with the publication year, the number of articles that have been cited for the first time during that year. The difference between the number of source articles and the cumulative number of articles that are cited at least once, is the number of uncited articles, as presented in Table 1.

Table 4 1955: 75 source articles

\begin{tabular}{|c|c|c|c|}
\hline year & $\begin{array}{c}\text { number of articles } \\
\text { cited for the first } \\
\text { time }\end{array}$ & year & $\begin{array}{c}\text { number of articles } \\
\text { cited for the first } \\
\text { time }\end{array}$ \\
\hline 1955 & 12 & 1964 & 2 \\
\hline 1956 & 17 & 1965 & 1 \\
\hline 1957 & 12 & 1966 & 0 \\
\hline 1958 & 4 & 1967 & 1 \\
\hline 1959 & 4 & 1968 & 1 \\
\hline 1960 & 2 & 1969 & 1 \\
\hline 1961 & 4 & 1970 & 1 \\
\hline 1962 & 1 & 1971 & \\
\hline 1963 & 0 & & \\
\hline
\end{tabular}

Table 5 1958: 77 source articles

\begin{tabular}{|c|c|c|c|}
\hline year & $\begin{array}{c}\text { number of articles } \\
\text { cited for the first } \\
\text { time }\end{array}$ & year & $\begin{array}{c}\text { number of articles } \\
\text { cited for the first } \\
\text { time }\end{array}$ \\
\hline 1958 & 7 & 1967 & 1 \\
\hline 1959 & 15 & 1968 & 0 \\
\hline 1960 & 10 & 1969 & 1 \\
\hline 1961 & 7 & 1970 & 1 \\
\hline 1962 & 7 & 1971 & 1 \\
\hline 1963 & 5 & 1972 & 0 \\
\hline 1964 & 3 & 1973 & 0 \\
\hline 1965 & 3 & 1974 & 1 \\
\hline 1966 & 2 & & \\
\hline
\end{tabular}


Table 6 1961: 122 source articles

\begin{tabular}{|c|c|c|c|}
\hline year & $\begin{array}{c}\text { number of articles } \\
\text { cited for the first } \\
\text { time }\end{array}$ & year & $\begin{array}{c}\text { number of articles } \\
\text { cited for the first } \\
\text { time }\end{array}$ \\
\hline 1961 & 8 & 1968 & 1 \\
\hline 1962 & 32 & 1969 & 3 \\
\hline 1963 & 18 & 1970 & 2 \\
\hline 1964 & 13 & 1971 & 2 \\
\hline 1965 & 4 & 1972 & 1 \\
\hline 1966 & 5 & 1973 & 0 \\
\hline 1967 & 4 & 1974 & 1 \\
\hline
\end{tabular}

Table 7 1964: 167 source articles

\begin{tabular}{|c|c|c|c|}
\hline year & $\begin{array}{c}\text { number of articles } \\
\text { cited for the first } \\
\text { time }\end{array}$ & year & $\begin{array}{c}\text { number of articles } \\
\text { cited for the first } \\
\text { time }\end{array}$ \\
\hline 1964 & 5 & 1973 & 1 \\
\hline 1965 & 35 & 1974 & 1 \\
\hline 1966 & 27 & 1975 & 1 \\
\hline 1967 & 17 & 1976 & 0 \\
\hline 1968 & 8 & 1977 & 0 \\
\hline 1969 & 7 & 1978 & 0 \\
\hline 1970 & 6 & 1979 & 1 \\
\hline 1971 & 2 & 1980 & 1 \\
\hline 1972 & 2 & 1981 & 1 \\
\hline
\end{tabular}

Table 8 1967: 301 source articles

\begin{tabular}{|c|c|c|c|}
\hline year & $\begin{array}{c}\text { number of articles } \\
\text { cited for the first } \\
\text { time }\end{array}$ & year & $\begin{array}{c}\text { number of articles } \\
\text { cited for the first } \\
\text { time }\end{array}$ \\
\hline 1967 & 36 & 1976 & 2 \\
\hline 1968 & 65 & 1977 & 2 \\
\hline 1969 & 34 & 1978 & 2 \\
\hline 1970 & 17 & 1979 & 1 \\
\hline 1971 & 10 & 1980 & 2 \\
\hline 1972 & 12 & 1981 & 1 \\
\hline 1973 & 10 & 1982 & 1 \\
\hline 1974 & 3 & 1983 & 1 \\
\hline 1975 & 2 & 1984 & 1 \\
\hline
\end{tabular}


Table 9 1970: 324 source articles

\begin{tabular}{|c|c|c|c|}
\hline year & $\begin{array}{c}\text { number of articles } \\
\text { cited for the first } \\
\text { time }\end{array}$ & year & $\begin{array}{c}\text { number of articles } \\
\text { cited for the first } \\
\text { time }\end{array}$ \\
\hline 1970 & 18 & 1978 & 4 \\
\hline 1971 & 55 & 1979 & 6 \\
\hline 1972 & 42 & 1980 & 6 \\
\hline 1973 & 19 & 1981 & 5 \\
\hline 1974 & 12 & 1982 & 5 \\
\hline 1975 & 12 & 1983 & 4 \\
\hline 1976 & 8 & 1984 & 3 \\
\hline 1977 & 4 & & \\
\hline
\end{tabular}

Table 10 1973: 418 source articles

\begin{tabular}{|c|c|c|c|}
\hline year & $\begin{array}{c}\text { number of articles } \\
\text { cited for the first } \\
\text { time }\end{array}$ & year & $\begin{array}{c}\text { number of articles } \\
\text { cited for the first } \\
\text { time }\end{array}$ \\
\hline 1973 & 38 & 1981 & 4 \\
\hline 1974 & 72 & 1982 & 6 \\
\hline 1975 & 69 & 1983 & 4 \\
\hline 1976 & 25 & 1984 & 5 \\
\hline 1977 & 21 & 1985 & 1 \\
\hline 1978 & 16 & 1986 & 2 \\
\hline 1979 & 8 & 1987 & 2 \\
\hline 1980 & 9 & & \\
\hline
\end{tabular}

Table 11 1976: 465 source articles

\begin{tabular}{|c|c|c|c|}
\hline year & $\begin{array}{c}\text { number of articles } \\
\text { cited for the first } \\
\text { time }\end{array}$ & year & $\begin{array}{c}\text { number of articles } \\
\text { cited for the first } \\
\text { time }\end{array}$ \\
\hline 1976 & 61 & 1983 & 5 \\
\hline 1977 & 106 & 1984 & 4 \\
\hline 1978 & 62 & 1985 & 3 \\
\hline 1979 & 27 & 1986 & 3 \\
\hline 1980 & 23 & 1987 & 2 \\
\hline 1981 & 4 & 1988 & 1 \\
\hline 1982 & 6 & & \\
\hline
\end{tabular}


Table 12 1979: 483 source articles

\begin{tabular}{|c|c|c|c|}
\hline year & $\begin{array}{c}\text { number of articles } \\
\text { cited for the first } \\
\text { time }\end{array}$ & year & $\begin{array}{c}\text { number of articles } \\
\text { cited for the first } \\
\text { time }\end{array}$ \\
\hline 1979 & 29 & 1986 & 4 \\
\hline 1980 & 192 & 1987 & 6 \\
\hline 1981 & 54 & 1988 & 1 \\
\hline 1982 & 19 & 1989 & 1 \\
\hline 1983 & 15 & 1990 & 2 \\
\hline 1984 & 7 & 1991 & 1 \\
\hline 1985 & 6 & 1992 & 1 \\
\hline
\end{tabular}

This document may be circulated freely

with the following statement included in its entirety:

Copyright 1999.

This article was originally published in

LIBRES: Library and Information Science

Electronic Journal_(ISSN 1058-6768) September 30, 1999

Volume 9 Issue 2.

For any commercial use, or publication

(including electronic journals), you must obtain

the permission of the authors.

Bry Mohan Gupta

National Institute of Science, Technology and Development Studies

Dr. K.S. Krishnan Marg, New Delhi 110012, India

E-mail: bmg@csnistad.ren.nic.in

and

Ronald Rousseau

KHBO, Zeedijk 101, 8400 Oostende, Belgium, and

UIA, IBW, Universiteitsplein 1, 2610 Wilrijk, Belgium

E-mail: ronald.rousseau@kh.khbo.be

To subscribe to LIBRES send e-mail message to

listproc@info.curtin.edu.au

with the text:

subscribe libres [your first name] [your last name] 
Return to Libre9n2 Contents

Return to Libres Home Page

CRICOS provider code: $00301 \mathrm{~J}$ 